\title{
Biosynthesis of Gold Nanoparticles Using Psidium Guajava Leaf Extract
}

\author{
Amel Taha ${ }^{1,2}$ and Mustaffa Shamsuddin ${ }^{1,3 *}$ \\ ${ }^{1}$ Department of Chemistry, Faculty of Science, Universiti Teknologi Malaysia, 81310 UTM Skudai, Johor, Malaysia \\ ${ }^{2}$ Department of Chemistry, Faculty of Science, Alneelain University, Khartoum, Sudan \\ ${ }^{3}$ Ibnu Sina Institue for Fundamental Science Studies, Universiti Teknologi Malaysia, 81310 UTM Skudai, Johor, Malaysia \\ Received 1 January 2013, Revised 29 March 2013, Accepted 15 April 2013, Available online 2 May 2013
}

\begin{abstract}
Nanomaterials are attracting a lot of attention nowadays as they show different chemical and physical properties that are dependent on their size and shape. Different techniques have been used for synthesis metal nanoparticles but the use of plants for synthesis of nanoparticles could be advantageous over other environmentally methods as this eliminates the cost and the non toxicity is main feature. Here a simple biosynthesis approach was applied and gold nanoparticles were synthesized by using psidium guajava leaf extract as reducing and capping agent. Two different parameters were studied which are the metal ion concentration and volume of plant broth. The synthesis of gold nanoparticles was also monitored as function of reaction time. The formation of gold nanoparticles was monitored by UV-Vis spectrophotometer and the size of particles was confirmed by X-Ray Diffraction (XRD), Transmission Electron Microscopy (TEM) techniques. TEM analysis showed that the AuNPs were mostly spherical in shape with an average size of 15 $\mathrm{nm}$. Fourier Transform Infrared (FTIR) spectroscopy that the active biomolecules present in the Psidium guajava leaf extract act as capping and stabilizing agent for the AuNPs.
\end{abstract}

| Gold Nanoparticle | Psidum Guajava | Extraction |

(B) 2013 Ibnu Sina Institute. All rights reserved. http://dx.doi.org/10.11113/mjfas.v9n3.95

\section{INTRODUCTION}

Currently, considerable attention has been made towards metal nanoparticles due to their unique properties that are different from their bulk metals. They have wide applicability in different areas including biology, chemistry, medicine and optoelectronics [1-3]. Many methods have been developed for the synthesis of metal NPs and most of these methods are based on chemical reduction and physical methods which are expensive, toxic and nonenvironmentally friendly. At present, there is a growing need to use non toxic, environmentally, and renewable materials for the synthesis of metal nanoparticles. Thus many attempts have focused on the use of green synthesis approach [4].

Gold nanoparticles exhibit novel optical and catalytic properties. They are also non-toxic and biocompatible. They have attracted considerable interest in a range of applications including electron microscopy marker [5], DNA sequencing [6], catalysis [7], wave guider [8], and in biomedical science [9]. While the chemical composition of nanoparticles is important, even more important is the morphology (size and shape) of the nanoparticles and their surface properties. Many biological systems, such as fungi, bacteria and plants have been studied for gold nanoparticles synthesis However, plantbased nanoparticle synthesis can be more advantageous over other biological system methods (microbial) since they are readily available, non toxic, the reaction rate for the synthesis of nanoparticles is very high and there is no need for complicated techniques to prepare the extract $[10,11]$.

Psidium guajava belong to the family of Maystrecea its widely growth in many countries and it has long history with folk medicine as it has antimicrobial, inflammatory activities antimalarial and antitumor [12-15]. The leaves also used to treat wounds, acne lesions [16)] cough and also for tooth pain and headache [17]. The anti-oxidant properties of psidium guajava aqueous leaf are due to the presence of active compounds including polyphenols, flavonoids, tannins, and saponins. The main active constituent in the plant was reported as quercetin derivatives [18]. In the present study, the use of aqueous leaf extract of psidium guajava as reducing and capping agent for gold nanoparticles synthesis is reported.

\section{EXPERIMENTAL SECTION}

\subsection{Material, methods and instruments}

Gold (III) chloride hydrate, $\left(\mathrm{HAuCl}_{4} \cdot 3 \mathrm{H}_{2} \mathrm{O}\right)$ obtained from Merck and used as received. A stock solution containing $25 \times 10^{3} \mathrm{M} \mathrm{HAuCl}_{4} .3 \mathrm{H}_{2} \mathrm{O}$ was prepared. Psidium guajava leaves used in these experiments were obtained locally from Pontian, Malaysia. The leaves were washed with distilled water to remove any dust or impurities and allowed to dry for 1-2 weeks at room temperature. The dried leaves were then grounded and sieved through a 20 
mesh sieve. $1.0 \mathrm{~g}$ of the powdered psidium guajava leaves was soaked in $100 \mathrm{ml}$ of deionized water for $24^{\prime}$ hours in a $500 \mathrm{~mL}$ Erlenmeyer flask. This was then followed by boiling the solution for 5 min after which it was filtered. The filtrate was collected and kept in refrigerator at $4^{\circ} \mathrm{C}$ for further experiments.

\subsection{Synthesis of Gold nanoparticles}

To study the effect of metal ion concentration, typically $1 \mathrm{ml}$ of psidium guajava leaf extract was added to a vigorously stirred $10 \mathrm{ml}$ of $\mathrm{HAuCl}^{-}$with varied concentration from $1 \mathrm{mM}$ to $10 \mathrm{mM}$. The same experiment was repeated by using the optimum concentration of $1 \mathrm{mM}$ whilst varying the volume of Psidium. guajava leaf extract (1-8 ml).

The gold nanoparticles solution obtained by bioreduction using psidium guajava leaf extract was centrifuged at $15,000 \mathrm{rpm}$ for $20 \mathrm{~min}$. Then the pellet was redispersed in deionized water to get a solution free of any protein or uncoordinated biological molecules

\subsection{UV-Vis Spectrophotometer analysis}

Bioreduction of $\mathrm{AuCl}_{4}^{-}$in aqueous solution was followed by periodic sampling, after diluting small aliquots $(1 \mathrm{ml})$ of sample with $2 \mathrm{ml}$ of deionized water The analysis was carried out using a PERKIN-ELMER UV-Vis spectrophotometer between $400-800 \mathrm{~nm}$

\subsection{X-ray Diffraction (XRD) measurement}

Dried powder of gold nanoparticles was examined by X-ray diffraction (XRD) patterns to determine the peak intensity, position and width. The X-ray diffractogram was obtained using Bruker D8 Advance powder diffractometer with $\mathrm{Cu} \mathrm{K} \alpha$ radiation $(\lambda=0.15418 \mathrm{~nm}, 40 \mathrm{kV}, 40 \mathrm{~mA})$ and were measured in the $2 \theta$ scale of $30-90$.

\subsection{Transmission Electron Microscopy (TEM) analysis}

The morphology of AuNPs was investigated by Transmission Electron Microscopy (TEM) using a JEOL JEM-2100 instrument operating at an accelerating voltage of $200 \mathrm{kV}$. A drop of synthesized colloidal AuNPs solution sample is deposited on carbon coated grids and followed by solvent evaporation.

\subsection{Fourier Transform Infrared Spectroscopy analysis}

After the bioreduction process had completed, the solution was centrifuged at $15,000 \mathrm{rpm}$ for $10 \mathrm{~min}$ to isolate the formed gold nanoparticles. The resulting solution was redispersed into $10 \mathrm{ml}$ of deionized water and this process was repeated three times. The FTIR spectroscopic analysis on the dried gold nanoparticles and the powdered psidium guajava leaf were performed using a Perkin-Elmer FTIR spectrometer in region from $400-4000 \mathrm{~cm}^{-1}$ at a resolution of $4 \mathrm{~cm}^{-1}$.

\section{RESULTS AND DISCUSSIONS}

\subsection{UV-Vis analysis}

The formation of gold nanoparticles was monitored by visual change in color and UV-Vis spectroscopy studies. The color of the reaction mixture had changed from pale yellow to ruby-red color after 10 mins due to the Surface Plasmon Resonance phenomena (SPR) that arise from the collective oscillation of free conduction electrons induced by interacting electromagnetic field [19].

The formation of gold nanoparticles can be monitored as a function of time (Fig. 1). It can be observed that the reaction was completed within $50 \mathrm{~min}$ of reaction after which the intensity of the SPR band showed little increased.

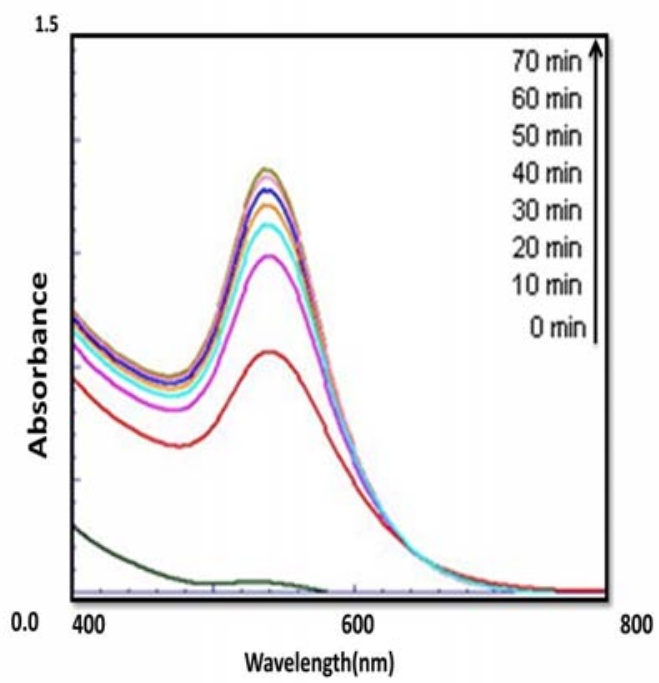

Fig. 1. UV-Vis spectrum recorded for gold nanoparticles as funtion of reaction time.

Fig. 2 shows the effect of metal ion concentration of the formation of gold nanoparticles. It was found that the metal ion concentration plays an important role in the formation of the nanoparticle. A sharp and strong peak centred at $529 \mathrm{~nm}$ was obtained at $1 \mathrm{mM}$ concentration (a). However, when the metal ion concentration was increased to $3 \mathrm{mM}$ (b), $5 \mathrm{mM}$ (c ) and $10 \mathrm{mM}$ (d), much broader peaks with lower intensities were observed. In addition, the absorbance maxima in all case had shifted to a much lower wavelength, suggesting the formation of much larger nanoparticles.

Fig. 3 shows the UV-Vis spectra of colloidal Au NPs synthesized using constant concentration of $\mathrm{HAuCL}_{4}$ at 1 $\mathrm{mM}$ but with different volume of the psidium guajava leaf extract; $1 \mathrm{ml}\left(\mathrm{a}_{1}\right), 2 \mathrm{ml}\left(\mathrm{a}_{2}\right), 4 \mathrm{ml}\left(\mathrm{a}_{3}\right), 6 \mathrm{ml}\left(\mathrm{a}_{4}\right)$ and $8 \mathrm{ml}\left(\mathrm{a}_{5}\right)$. As 
can be observed, an increased in the volume of leaf extract led to the decreased in the SPR band intensity with no significant shift of the absorption peak. In particular at volume of 6 and $8 \mathrm{ml}$, the absorption bands had broadened with slight shifted to longer wavelength. The SPR band depends on the particle size, shape and chemicals surrounding of the adsorbed species on the surface. In the present study, $1 \mathrm{ml}$ of leaf extract is sufficient for completion of the bioreduction. However, the control over nanoparticles synthesis by volume of leaf used seems to be dependent on the procedure of the extract preparation and nature of the plant used.

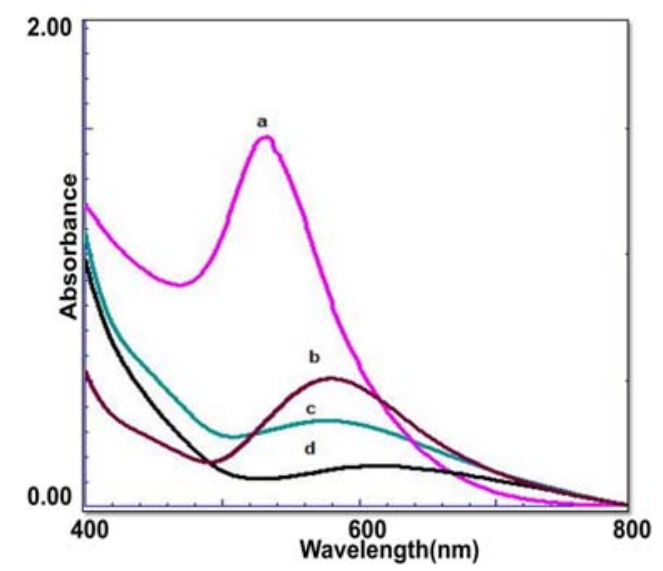

Fig. 2 UV-Vis spectrum of gold nanoparticles obtained at different metal ion concentration (a) $1 \mathrm{mM}$ ), (b) $3 \mathrm{mM}$, (c) 5 $\mathrm{mM}$, (d) $10 \mathrm{mM}$

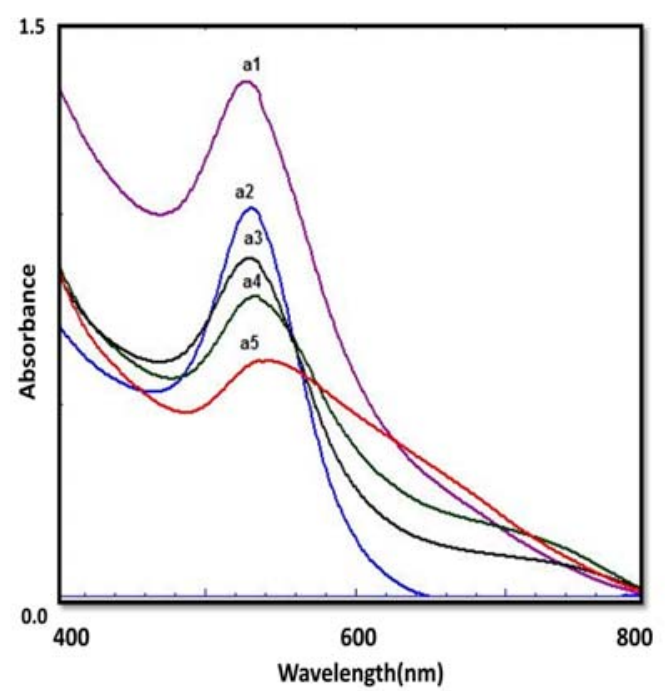

Fig. 3. UV-Vis spectrum of gold nanoparticles obtained at different plant extract volumes $\mathrm{a}_{1}(1 \mathrm{ml}), \mathrm{a}_{2}(2 \mathrm{ml}), \mathrm{a}_{3}(4 \mathrm{ml}), \mathrm{a}_{4}$ $(6 \mathrm{ml})$ and $\mathrm{a}_{5}(8 \mathrm{ml})$

\subsection{XRD Analysis}

Figure 4 shows the X-ray diffraction patterns observed for the biosynthesized gold nanoparticles using psidium guajava leaf extract. Five Bragg reflection peaks corresponding to (111), (200), $(220\},\{311\}$ and $\{222\}$ sts of lattice planes are observed that may be indexed to the face centered cubic (fcc) structure of gold. The XRD diffraction pattern clearly shows that the gold nanoparticles formed by the reduction of AuCl4- ions by the psidium guajava leaf extract are highly crystalline. The broadening of the peaks indicates the formation of nanoparticles. The diffraction peak corresponding to the (111) lattice plane shows the strongest intensity compared to the other peaks suggesting that (111) is the predominant orientation. The mean size of nano gold was calculated by Debye- Scherrer equation [20]. From the equation the average size of gold nanoparticles found $15 \mathrm{~nm}$ which in agreement with TEM studies

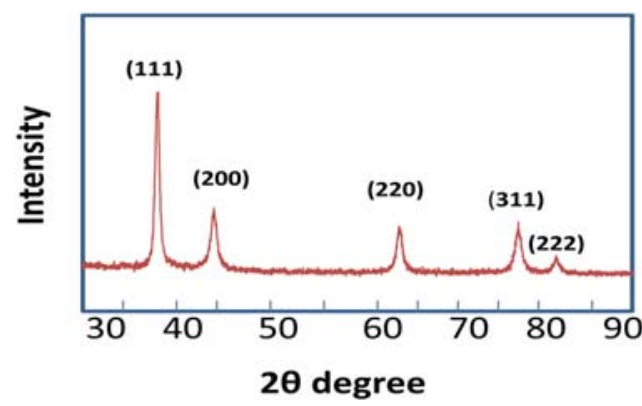

Fig. 4. XRD diffractogram of gold nanoparticles synthesized by reduction of $\mathrm{AuCl}_{4}^{-}$ions using broth of Psidium guajava leaf

\subsection{TEM Analysis}

Fig. 5 showed the TEM images of the biosynthesized AuNPs. From the figure, it is clear that most of the particles are spherical in nature with a few of them are irregular in shape. The diameter of the spherical AuNPs varied from 10 $\mathrm{nm}$ to $23 \mathrm{~nm}$, with an average size of $15 \mathrm{~nm}$. The formation of this shape may be attributed to the protective and reductive biomolecules present in the psidium guajava leaf extract.

\subsection{FTIR Analysis}

FTIR measurements were carried out to identify the active biomolecules present in the psidium guajava leaf broth that were responsible for the reduction and capping of the bioreduced gold nanoparticles. Fig. 6 represents the FTIR spectrum of the gold nanoparticles. The figure shows absorption peaks at $1033 \mathrm{~cm}^{-1}$ (ether linkages), $1384 \mathrm{~cm}^{-1}$ (O-H bending), $1447 \mathrm{~cm}^{-1}(\mathrm{NH}), 1609 \mathrm{~cm}^{-1}$ (amide I) and $3450 \mathrm{~cm}^{-1}$ (O-H stretching) suggest the presence of proteins, alkaloids and terpenoids absorbed on the surface of the gold 
nanoparticles [21]. This observation showed these biomolecules that contain many $\mathrm{C}=\mathrm{O}$ or $\mathrm{N}-\mathrm{H}$ groups play an important role in the bioreduction and capping of the nanoparticles. The band around $3450 \mathrm{~cm}^{-1}$ indicates the presence of polyphenolic $\mathrm{OH}$ group. Thus, it the biosynthesized gold nanoparticles are probably capped by functional groups on such as proteins and polyphenols through the interactions of free amine and carbonyl groups in the proteins as well as the hydroxyl groups in the polyphenols.

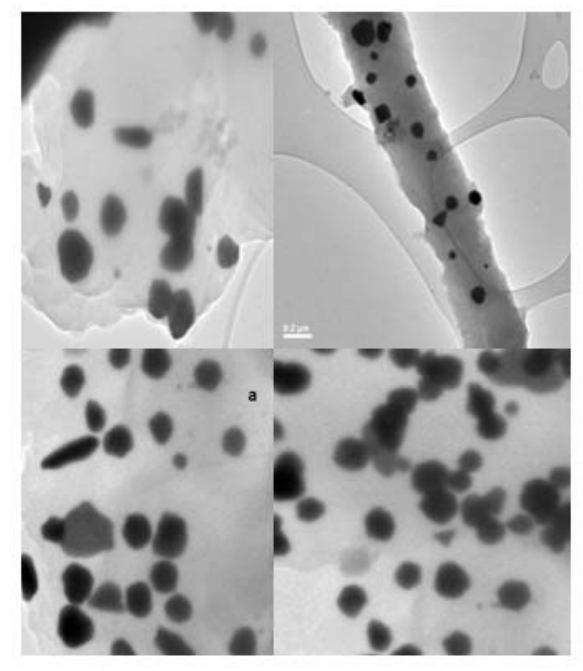

Fig. 5. TEM images for AuNPs by using $1 \mathrm{mM} \mathrm{HAuCl}_{4}{ }^{-}$and $1 \mathrm{ml}$ of psidium gujava leaf extract

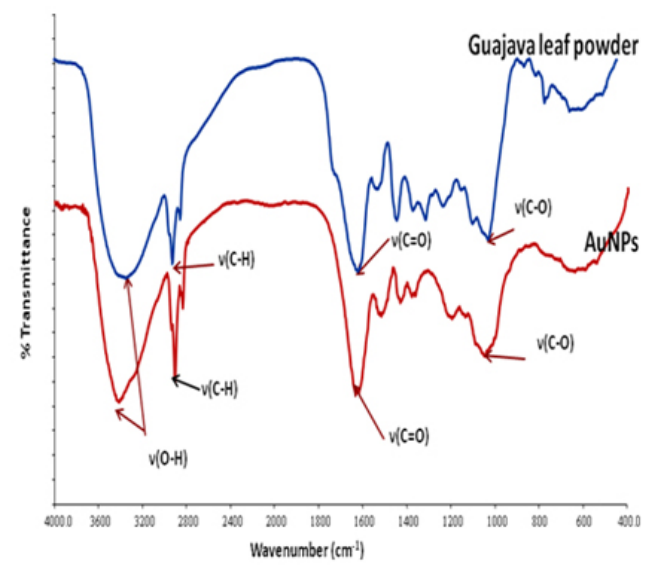

Fig. 6. FTIR absorption spectrum for [a] psidium guajava leaf, [b] biosynthesized gold nanoparticles.

\section{CONCLUSIONS}

In this study, we have reported a simple, ecofriendly and low cost method for the biosynthesis of gold nanoparticles. The most important feature of this procedure is that it avoids the use of any toxic and hazardous chemicals which satisfies the green chemistry approaches for metal nanoparticles synthesis. It was observed that several factors such as volume of leaf extract and metal ions concentration can play important role in the nanoparticles shapes and sizes. The water soluble phythochemicals in the psidium guajava leaf extract were principally responsible for the reduction of gold ions and the stabilization of the nanoparticles.

\section{ACKNOWLEDGEMENTS}

The authors thank the Ministry of Higher Education (MOHE), Malaysia and Universiti Teknologi Malaysia for providing financial assistance through Research University Grant Vot No. 00H13.

\section{REFERENCES}

[1] K.B. Narayanan, N.Sakthivel, Mater. Lett. 62(2008) 4588-4590.

[2] F. Mafune, J. Kohoo, Y. Takada, T. Kondow, J. Phys. Chem.B. 106 (2002) 7575-7577.

[3] N. Wang, Y. Cai, R .Q.Zhang, Mater. Sci. Eng. Rep., 60(2008), 1-5.

[4] A. Ahmad and M. Sastry, Nat. Mater., 3(2004) 482-488.

[5] W. Baschong and N.G. Wrigley., J. Elctron. Microsc. Tech. 14(1990) 313-323.

[6] R. Elghanian, J.J. Storhoff, R.C. Mucic, R.L. Letsinger, and C.A. Mirkin., Science 277 (1997) 1078-1081.

[7] J. Li, C. Ma, X. Xu, J. Yu, Z. Hao, and S. Qiao., Sci. Technol. 42 (2008) 8947-8951.

[8] L.N. Ng, B.J. Luff, M.N. Zervas, and J.S. Wilkinson., Optics Commun. 208 (2002) 117-124.

[9] Huang, SH, Clin. Chim. Acta. 373 (2006) 139-43.

[10] K. Govindaraju, V. Kiruthiga, R. Manikandan, T. Ashokkumar and G. Singaravelu, Mater. Lett. 65 (2011) 256-259.

[11] S. Shankar, A. Rai, A. Ahmad and M. Sastry, J. Colloid Interface Sci. 275 (2004) 496-502.

[12] H.Arimad and G. Danno, Biosci. Biotechnol. Biochem. 66 (2002) 1727-1730.

[13] K. F. Chah, C.A. Eze, C. E. Emuelosi and C.O. Esimone, J. Ethnopharmacol. 140 (2006) 164-167.

[14] JA. Ojewole, Clin. Pharmacol. 28 (2006) 441-446.

[15] G. R. Prabu, A. Gnanamani, S. Sadulla, .J. Appl. Microbiol. 101 (2006) 487-495.

[16] F. Qadan, A.J. Thewaini, D. A. Ali, R. Afifi, A. Elkhawad and K.Z. Matalka., Am. Chin. Med. 339 ( 2005) 197-204.

[17] F. Razak, A. Othman, R.Y. Rahim, Z. H, Journal of Oral Science 48 (2006) 71-75.

[18] S. Ross, I A, Medicinal Plants of The World, Humana Press, New Jersey, USA, 48 (1999).

[19] S.L Smitha, D. Philip, K.G. Gopchandran, Spectrochim. Acta A 74 (2009) 735-739.

[20] H. Borchert, E.V. Shevchenko, A. Robert, I. Mekis, A. Komowski, G. Grubel, Langmuir 21(2005) 1931-6.

[21] D. Philip, Spectrochim. Acta A 73 (2009) 374-381 